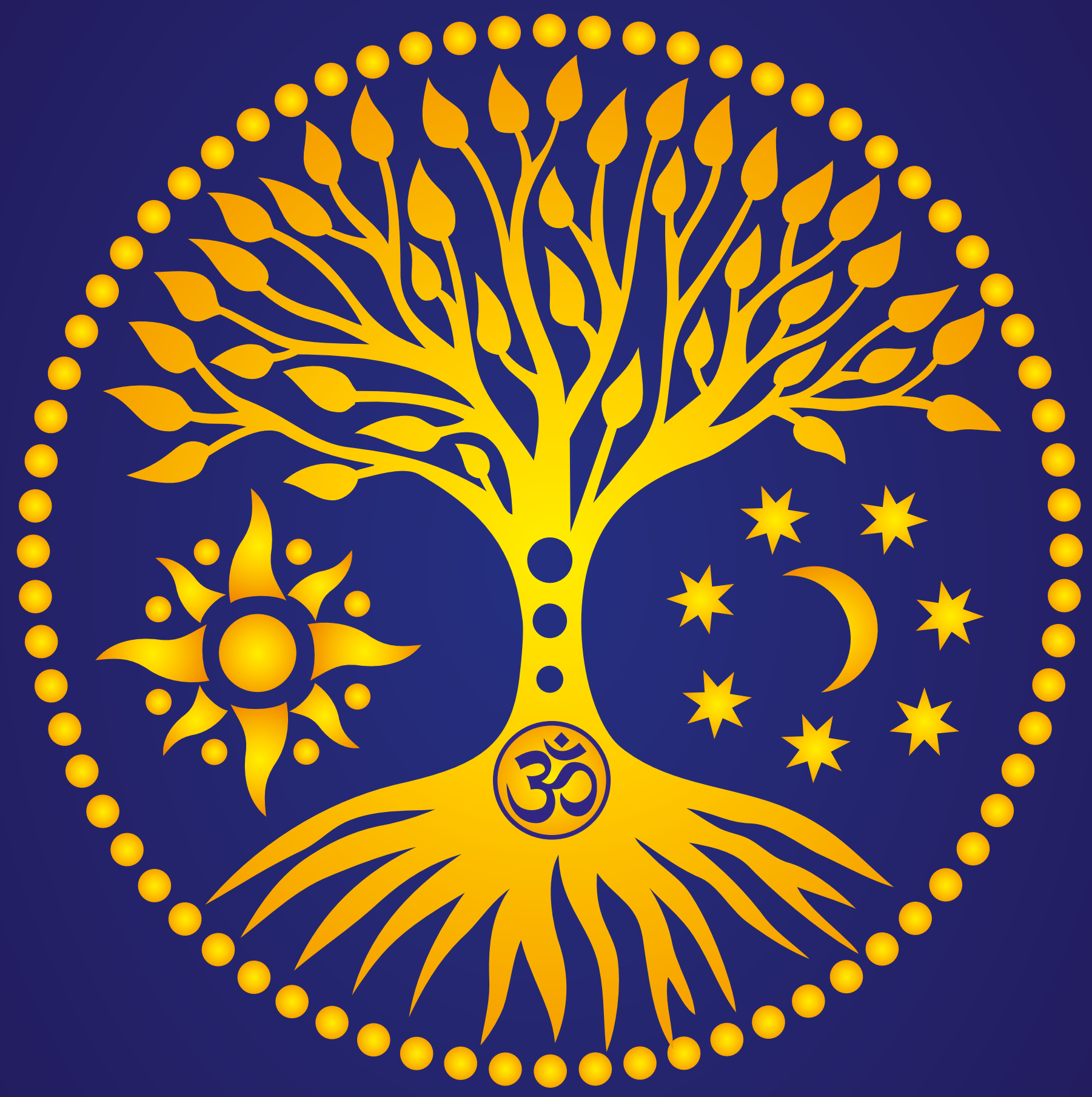




\section{OS GANHOS DE UMA AGRICULTURA SUSTENTÁVEL}

I POR SANJAY LANKA

\section{Visando preservar os recursos naturais, beneficiar os pequenos agricultores e promover meios de subsistência para as comunidades locais, uma cooperativa na Índia aposta nos serviços ecossistêmicos e na agroecologia para gerar melhores resultados ambientais, econômicos e sociais.}

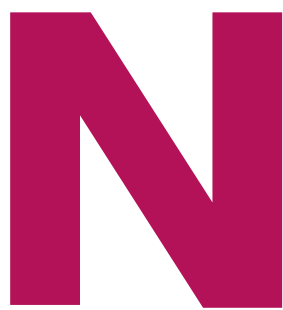

o mundo inteiro, o pequeno agricultor vem enfrentando uma crise. A redução do valor recebido pelos produtores de commodities agrícolas desafia a sobrevivência de quem as cultiva. Tome-se o exemplo do café. Embora o valor gerado pela indústria cafeeira global tenha quase dobrado nos últimos dez anos para cerca de US\$ 90 bilhões, os cafeicultores receberam poucos benefícios desse crescimento. Isso porque eles são remunerados pelas cotações internacionais em bolsa de valores, e, por causa da queda no preço nos últimos anos (veja no gráfico da página 29), muitos foram obrigados a abandonar suas plantações.

Apesar da dominação mundial pelo mercado de commodities, o setor de cafés especiais, focado em grãos de alta qualidade e com um sistema de produção sustentável, alcança preço superior ao da commodity. O Brasil, como o maior produtor mundial de café, tem muito a crescer nesse nicho. Para isso, pode buscar inspiração em exemplos internacionais bem-sucedidos, como o da Sociedade Cooperativa de Pequenos e Marginais Agricultores Tribais (Small and Marginal Tribal Farmers Mutually Aided Cooperative Society - SAMTFMACS), uma cooperativa de café com sede no estado de Andhra Pradesh, no sul da Índia. Atualmente, ela possui mais de 25 mil membros, o que a torna uma das maiores cooperativas de café certificadas com comércio justo e orgânico do mundo.

\section{A CRISE DO CAFÉ \\ E SUAS ALTERNATIVAS}

Um dos grandes desafios do negócio do café é que a maior parte do lucro fica onde o consumidor está localizado. Enquanto supermercados, restaurantes e cafeterias ganham, os produtores, principalmente aqueles pequenos que investem em grãos de qualidade, muitas vezes não recebem o suficiente para pagar os custos e atingir o ponto de equilíbrio financeiro. 


\section{A agricultura industrial compromete os agroecossistemas tradicionais com fertilizantes e pesticidas químicos. $O$ alto custo desses produtos exige que os agricultores tomem empréstimos e não consigam gerar renda para sair do endividamento.}

Pesam nessa conta as despesas cada vez mais altas de insumos de energia, fertilizantes e pesticidas químicos, que fazem com que os agricultores tomem empréstimos e entrem em um ciclo de endividamento do qual não conseguem mais sair.

Mesmo os produtores que ainda conseguem obter ganhos, por terem uma produção massificada e automatizada, deveriam se preocupar com o seu futuro. A agricultura industrial compromete os agroecossistemas tradicionais. Os fertilizantes químicos destroem o solo. De acordo com estudo do autor deste artigo em conjunto com Iqbal Khadaroo e Steffen Böhm, os solos em todo o mundo perderam, em média, pelo menos 1 ou 2 pontos percentuais de matéria orgânica nos $30 \mathrm{~cm}$ superiores desde que os fertilizantes químicos passaram a ser amplamente utilizados. Isso equivale a cerca de 150 mil a 205 milhões de toneladas de matéria orgânica, resultando na emissão de 220-330 milhões de toneladas de $\mathrm{CO}_{2}$ no ar, ou $30 \%$ do excesso atual de $\mathrm{CO}_{2}$ na atmosfera. Esse sistema intensivo de cultivo também tem impacto negativo na produção. Os últimos números do Rabobank, de novembro de 2019, estimam redução na produção de café arábica de 3,2 milhões de sacas de $60 \mathrm{~kg}$ para a safra 2020/21.

Como alternativa a esse modo de produção, o setor dos cafés especiais já responde por mais da metade do café consumido nos Estados Unidos. A produção de grãos de alta qualidade é baseada na agroecologia, definida como a ciência que fornece os princípios e conceitos ecológicos para o gerenciamento de ecossistemas agrícolas produtivos que conservam os recursos naturais. Ela propõe uma visão holística do agroecossistema, minimizando insumos externos, como fertilizantes e pesticidas, e produzindo, portanto, melhores resultados ambientais, econômicos e sociais para os agricultores.

Há evidências de que os agricultores que aplicam os princípios da agroecologia estão em uma posição melhor para garantir meios de vida sustentáveis. A eliminação de fertilizantes químicos tem o potencial de reduzir as emissões globais anuais de efeito estufa em até $10 \%$. A mudança completa para esse modo de produção poderia permitir que os agricultores reconstruíssem matéria orgânica nos solos de todo o mundo e, dentro de 50 anos, capturassem cerca de dois terços do atual excesso de $\mathrm{CO}_{2}$ na atmosfera. Mesmo com a pressão para reduzir os preços também dos produtores de grãos de alta qualidade, há iniciativas no mundo que vêm conseguido vencer os desafios.

\section{A EXPERIÊNCIA DE UMA COOPERATIVA INDIANA}

A eficácia do uso de uma abordagem agroecológica pode ser vista pela experiência da SAMTFMACS. Criada em 2001, ela utiliza os serviços ecossistêmicos da natureza para melhorar os meios de subsistência das comunidades da região. Seus membros não dependem de sementes comerciais para o cultivo e têm usado diferentes sementes nativas que economizam a cada ano em sua colheita.

Os membros da cooperativa também foram afetados negativamente pela crise do café. Antes da fundação da SAMTFMACS, os cafeicultores da região estavam à mercê dos comerciantes, que compravam os grãos a um preço baixo para revendê-los a valores bem mais altos. Assim, a cooperativa, em parceria com a Fundação Naandi e a empresa francesa Danone, iniciou um projeto agroflorestal com o objetivo de fornecer fontes alternativas de receita, reduzindo a dependência do café.

Como o café de alta qualidade é cultivado à sombra, o projeto agroflorestal consistiu em criar sombra para o café usando árvores frutíferas, plantando cerca de seis milhões de mudas durante cinco anos em 6 mil hectares. Isso também forneceu os meios para a criação de hábitats nos quais a biodiversidade poderia retornar e fornecer serviços ecossistêmicos aos cafeicultores. Por exemplo, as populações de aranhas puderam multiplicar-se e fornecer controle natural de pragas, reduzindo o uso de pesticidas sintéticos que prejudicam a biodiversidade e colocam em risco a saúde do agricultor. Além disso, dado que as árvores sequestram carbono, isso permitiu à comunidade ganhar dinheiro extra com a venda de créditos de carbono para o mercado internacional. Ademais, à medida que as árvores frutíferas amadureciam, forneciam uma fonte alternativa de receita 


\section{EVOLUÇÃO DA COTAÇÃO DO CAFÉ NA BOLSA DE NOVA YORK (EM US\$/LIBRA*)}

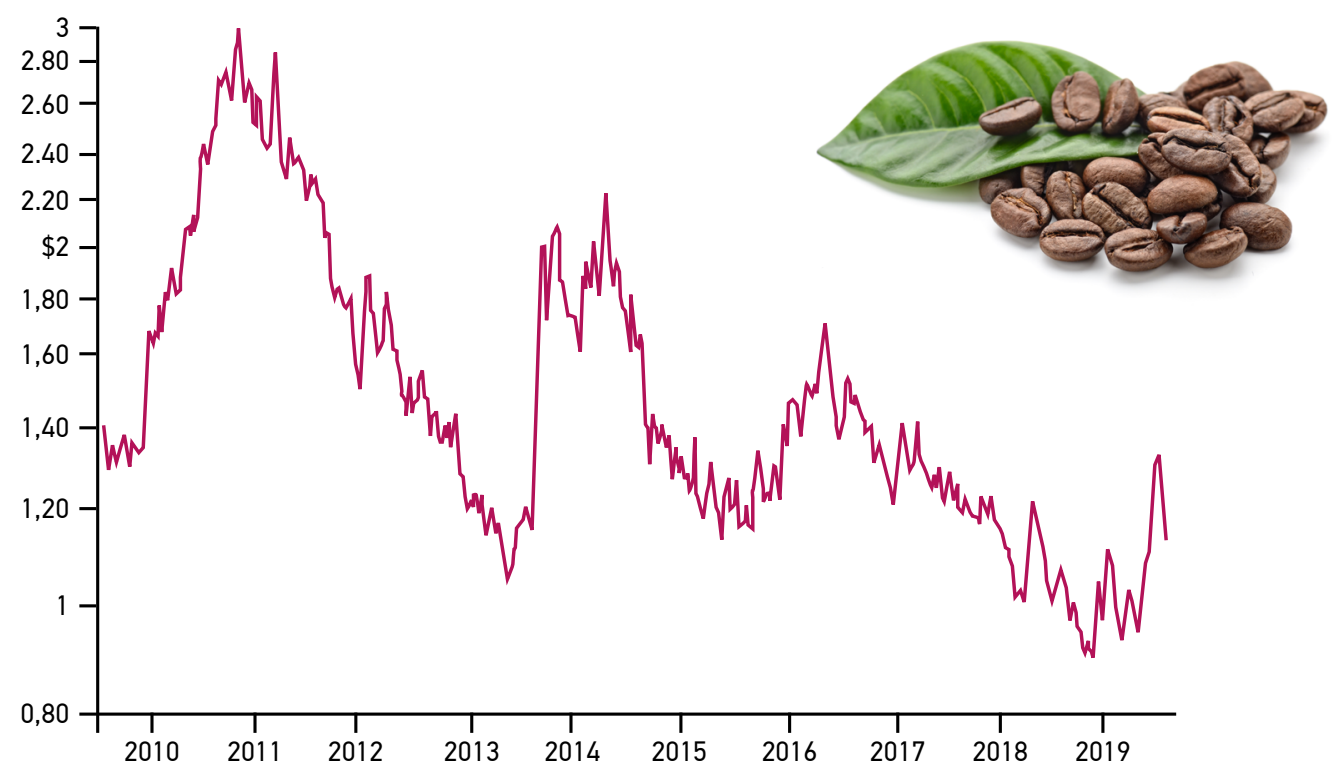

*MEDIDA UTILIZADA PARA MENSURAR A QUANTIDADE DE CAFÉ E QUE EQUIVALE A 0,45 KG FONTE: MACROTRENDS.NET

para os agricultores, permitindo-lhes a oportunidade de diversificar seus meios de vivência, a fim de não depender apenas do café.

O projeto começou com o plantio de um milhão de mudas em 2011, 2012 e 2013. Na fase seguinte, em 2014, foi introduzido café sob a sombra de árvores em 3 mil hectares. As árvores foram plantadas em áreas que não vinham gerando renda nem tinham biodiversidade, pois o solo havia sido degradado pela prática da agricultura com o uso de produtos químicos. As atividades realizadas no projeto agroflorestal, como o plantio de árvores com a prática da agricultura biodinâmica, restauraram a fertilidade do solo e permitiram que os cafeicultores economizassem dinheiro, por não terem de comprar fertilizantes químicos.

Além dos benefícios observados nas plantações, o projeto também foi bem-sucedido na comercialização. Como a cooperativa não possuía experiência em marketing nem em comércio internacional, conseguiu alavancar seu relacionamento com a Danone para exportar seu café para a França. Com a marca Araku, passou a competir com os cafés populares de Sumatra e Colombo e foi o primeiro café indiano a ganhar o prestigioso Prêmio Prix Epicures OR 2018, em Paris.

Em 2016 e 2017, o governo de Andhra Pradesh introduziu a abordagem desenvolvida como parte do projeto agroflorestal a todos os agricultores do estado. Em função da economia acumulada, por não utilizar fertilizantes e pesticidas, essa ação foi chamada de agricultura natural com orçamento zero (Zero Budget Natural Farming - ZBNF). Em um ano, cerca de 163 mil agricultores em 972 aldeias de 13 distritos de Andhra Pradesh adotaram essas práticas. Em setembro de 2018, o número de agricultores inscritos no ZBNF era de 354 mil, com planos para cobrir seis milhões de agricultores em mais de 12 mil aldeias até 2024 e toda a área cultivável no estado, cerca de 8 milhões de hectares, até 2026. Esse exemplo constitui, portanto, uma forte evidência de que uma prática sustentável pode ser uma alternativa favorável em termos econômicos, sociais e ambientais.
PARA SABER MAIS:

Sanjay Lanka, Iqbal Khadaroo e Steffen Böhm. Agroecology accounting: biodiversity and sustainable livelihoods from the margins. Accounting, Auditing \& Accountability Journal, v.30 n.7. 2017 doi org/10 1108/AAAJ-12-2015-2363

- Sanjay Lanka. Social Entrepreneurship in the Agrifood Sector: Smallholder Farmer Cooperatives. Emerging Business Values. In: Frank Birkin e Thomas Polesie (orgs.). Intrinsic Capability Implementing Intrinsic Sustainable Development for an Ecological Civilisation, 2019. Zareen Pervez Bharucha, Sol Bermejo Mitjans e Jules N Pretty. Towards Redesign at Scale Through Zero Budget Natural Farming in Andhra Pradesh, India. International Journal of Agricultural Sustainability, v.18, n.1, 2020. doi.org/10.1080/14735903.2019.1694465

SANJAY LANKA > Professor da FGV EAESP > sanjay.lanka@fgv.br 